http://jmscr.igmpublication.org/home/ ISSN (e)-2347-176x ISSN (p) 2455-0450 crossref DOI: https://dx.doi.org/10.18535/jmscr/v9i4.06

\title{
Pneumatosis Cystoides Intestinalis: A Report of 2 Cases
}

\author{
Authors \\ Dr Anchana Gulati ${ }^{1}$, Dr Shobha Mohindroo ${ }^{2}$, Dr Ishant Sharma ${ }^{3}$, Dr Shikha Sharma ${ }^{4 *}$ \\ ${ }^{1}$ Associate Professor, Pathology Department, IGMC Shimla \\ ${ }^{2}$ Associate Professor, Pathology Department, IGMC Shimla \\ ${ }^{3}$ Junior Resident, Pathology Department, IGMC Shimla \\ ${ }^{4}$ Senior Resident, Pathology Department, IGMC Shimla \\ *Corresponding Author
}

Dr Shikha Sharma

\begin{abstract}
Pneumatosis cystoides intestinalis (PCI) is a rare condition, associated with a variety of diseases. The presenting clinical picture is usually variable and represents a diagnostic challenge for the clinician. In the present paper we describe PCI, its common and an uncommon clinical presentation and pathological findings. Ours is a case report of 2 cases, both of which presented in a different clinical setting confirming that, apart from asymptomatic cases, the clinical presentation of PCI may be widely different. Our findings also point out that clinicians and endoscopists should be aware of the possible presentations of PCI in order to correctly manage the patients with PCI and avoid unnecessary surgeries.
\end{abstract}

\section{Introduction}

Pneumatosis cystoides intestinalis (PCI) is a rare entity with a reported incidence of $0.03 \%$. It is characterized by the presence of numerous gaseous cysts containing nitrogen, hydrogen and carbon dioxide in the intestinal submucosa and subserosa $^{(1,2)}$. Du Vernoi described PCI first in 1783 and later Koss subcategorized it in $1952^{(3)}$. The exact etiology of the disease is still unknown however PCI may arise in association with colonoscopies $^{[4]}$, ileal surgery ${ }^{[5]}$, chronic pulmonary disease ${ }^{[6]}$, connective tissue disorders ${ }^{[7]}$ and ingestion of sorbitol ${ }^{[8]}$ or lactulose ${ }^{[9]}$. Lesions of PCI are mainly located in the colon (46\%) and small intestine $(27 \%)$, followed by the large and small intestine $(7 \%)$ and stomach $(5 \%)^{[10]}$. There is no characteristic clinical presentation of pneu- matosis. In primary PCI, the clinical manifestations are nonspecific, such as abdominal pain $(59 \%)$, diarrhea (53\%), nausea and vomiting $(14 \%)$, mucus in stool $(12 \%)$, and hematochezia (12\%) [1611]. In secondary PCI, patient presents with primary disease manifestations, although about $3 \%$ of the patients with secondary PCI complain of complications, including pneumoperitoneum, volvulus, intestinal obstruction, and intestinal ischemia [1611,1712, 1813-2015]. There has been an aruguemnt in literature that the cystic spaces of pneumatosis intestinalis are the gas (air)-distended lymphatic channels secondary to the entry of bowel luminal gas (air) into the bowel wall in various conditions in which the mucosal integrity is lost.(1416) 


\section{Case Report}

\section{Case 1}

A 44 years old male patient presented with complains of non-progressive, non radiating, colicky upper abdominal pain, abdominal distention, non-bilous, non-blood stained vomitting and non-passage of flatus for the past 4 days. Patient had similar complains multiple times in the past 5 years. The patient was a chronic smoker and was a known case of COPD and abdominal koch. On physical examination, there was abdominal distention. On palpation of abdomen, there were multiple firm intraabdominal lumps ranging in size from $3 \times 3 \mathrm{~cm}$ to $4 \times 4 \mathrm{~cm}$ in the right inguinal fossa. Radiological examination suggested multiple cystic lesions in the submucosa of the ileum. The patient thus underwent exploratory laprotomy with resection of multiple sessile and pedunculated air filled vesicles bearing segment of ileum with ileal-ileal anastamosis. The specimen was then sent to the histopathology lab for further examination. On gross examination 2 samples were received. A 75 $\mathrm{cm}$ long segment of ileum was received, outer surface of ileal segment was studded with numerous coalesced grape-like vesicles of variable size, ranging in diameter from $0.2-0.5 \mathrm{~cm}$ (fig.1). Resection margins also revealed presence of vesicles. On cutting through, the vesicles were filled with gas. On cut opening the ileum through the anti-mesentric border, the mucosa was focally preserved and the vesicles were projecting into the lumen focally. Separately, in the second sample, a single grey-white globular soft tissue piece (mesenteric lymph node) measuring about $1 \mathrm{~cm}$ in diameter was received. Cut-section was solid, tanbrown in colour. Microscopic examination of the ileal wall with grape like vesicles revealed normal mucosa with denuded epithelial lining of some of the villi and focally seen cystically dilated spaces projecting on the surface of the mucosa. Submucosa revealed dilated congested blood vessels, edema and cystically dilated spaces lined by histiocytic multinucleated giant cells merging with endothelial cells and chronic inflammatory cells (fig.2). Bundles of muscularis propria reveal edema and prominent myentric plexus. Serosal surface revealed numerous cystically dilated spaces (fig.4) of variable size lined by flattened endothelium, chronic inflammatory cells and multinucleated histiocytes. Additionally, hyaline nodules, vascular congestion, lymphocytic inflammatory infiltrate, aggregates of hemosiderin laden macrophages and collections of histiocytic giant cells are also seen. Resection margins also focally revealed presence of cystically dialated vesicles. Microscopy of the the separately sent mesenteric lymph node revealed features of an old healed tuberculosis- comprising of a well circumscribed nodule with marked areas of necrosis in centre surrounded by foci of hyalinization and scattered lymphocytes and histiocytes. A focus of ill defined epithelioid cell granuloma along with occasional langhan's type giant celsl also seen. Based on the above findings, the histological diagnosis of Pneumatosis Cystoides Intestinalis (ileal segment) with involved resection margins was signed off.

\section{Case 2}

A 45-year-old man presented to the surgery department with upper abdominal pain, obvious abdominal distension, bloody stools tenesmus, fever and night sweats. Patient was a known case of celiac disease and was on a gluten free diet for the past 2 years. The patient suffered similar episode of abdominal pain and bloody stools 3 months prior as well, but did not visit the hospital that time as the symptoms subsided after 3 days. Clinically, complication of celiac disease with intestinal lymphoma was postulated. Abdominal $\mathrm{X}$-ray showed multiple intraluminal gas pockets in the ileum. Colonoscopy revealed grape-like or beaded subepithelial lesions, a few of them with erythematous mucosa distributed throughout the ileum. Hence, exploratory laprotomy with resection of the gas filled pockets bearing segment of ileum with ileal-ileal anastamosis. On gross examination, a $24 \mathrm{~cm}$ long segment of ileum was received. Outer surface was unremarkable. Cut 


\section{JMSCR Vol||09||Issue||04||Page 30-35||April}

surface showed multiple cystic vesicles in the wall. Resection margins were also involved by the cystic vesicles grossly. An ulcer measuring $0.7 \mathrm{~cm}$ in diameter was identified at one end of the ileal segment. Microscopic examination of the sections from the intestinal wall with cysts revealed normal ileal mucosa with focal ulceration. Lamina propria showed mixed inflammatory cells comprising of lymphocytes, macrophages, few plasma cells, neutrophils and eosinophils. Submucosa revealed edema, dilated congested blood vessels, and many cystically dialated spaces lined by histiocytes, multinucleated giant cells merging with endothelial cells and chronic inflammatory cells (fig.5,6). Resection margins were also involved by the cystically dilated spaces. Hisologically, the diagnosis of Pneumatosis Cystoides Intestinalis was given.

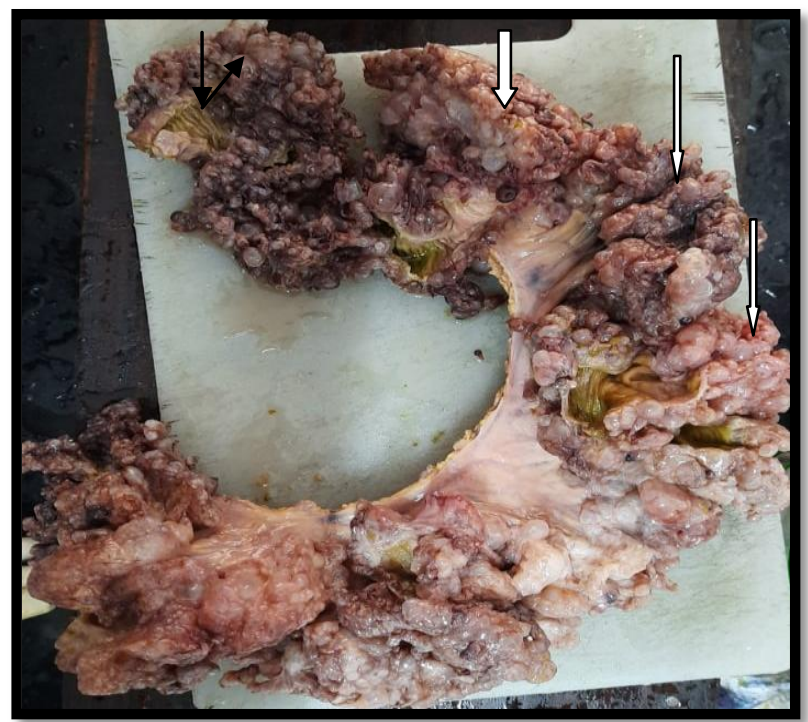

Fig.1. Ileal segment: normal mucosa (black arrow, left top); numerous coalesced air filled grape-like vesicles studded through the serosal surface. (white arrows)

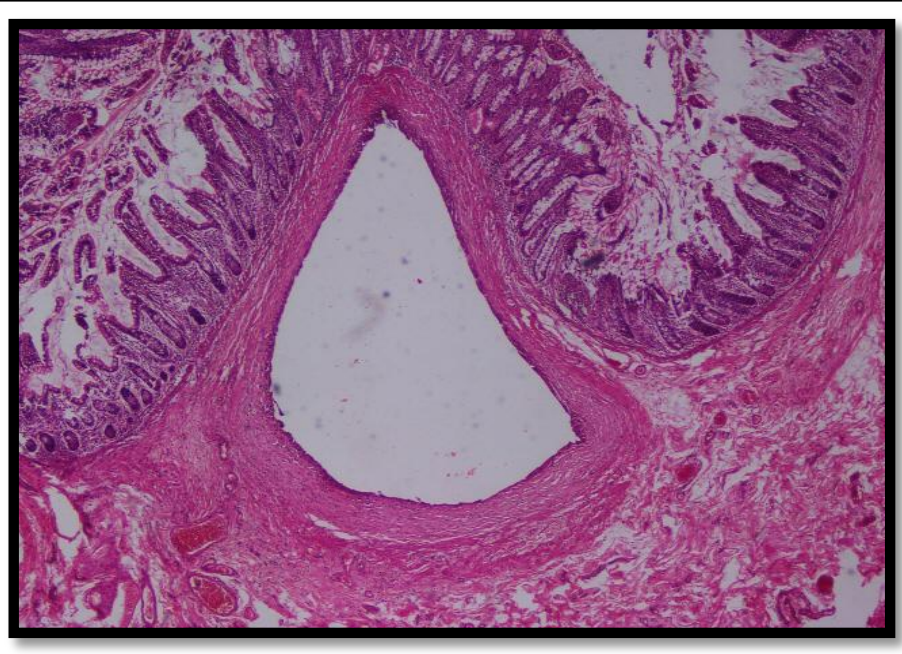

Figure 2 (10x) Normal intestinal mucosa and submucosal cyst. (Case 1)

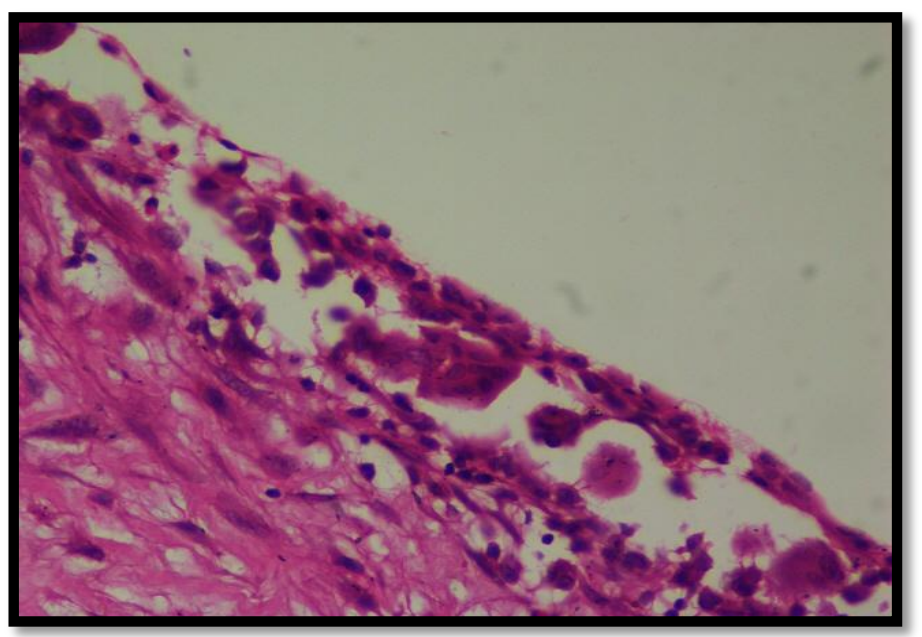

Fig. 3 (100x) Submucosal cyst (in fig.2) lined by histiocytic multinucleated giant cells merging with endothelial cells and chronic inflammatory cells. (Case 1)

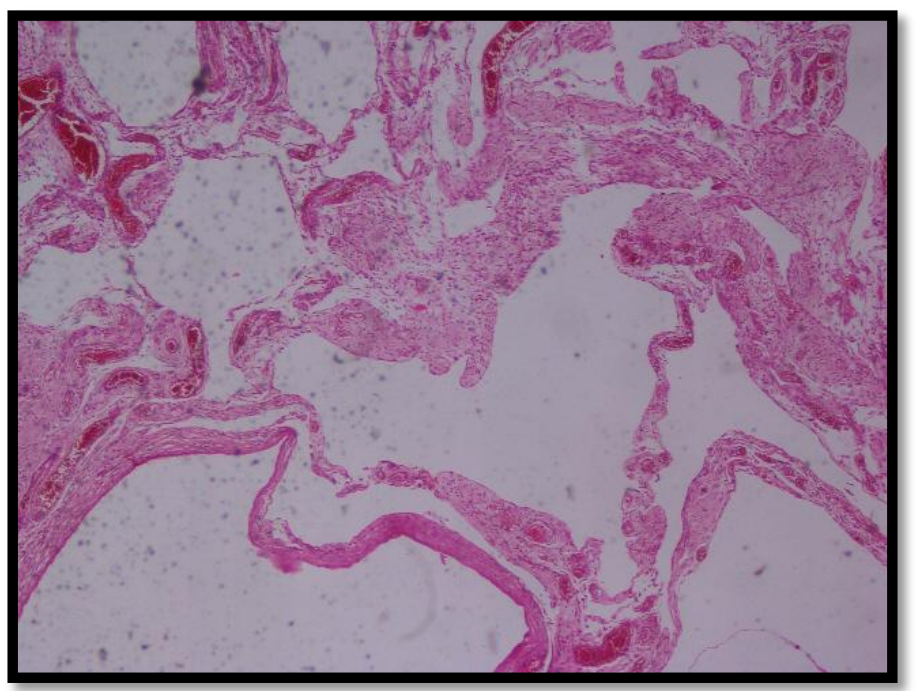

Fig. 4 (10x) Numerous cystic spaces on the serosal surface. (Case 1) 


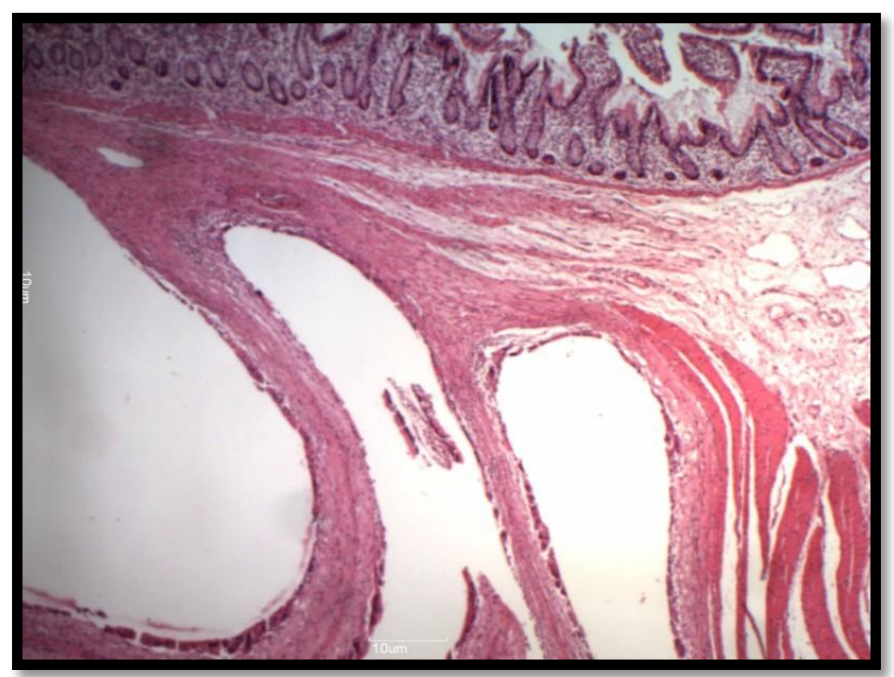

Fig. $5(10 x)$ normal intestinal lining with submucosal cystically dilated spaces. (Case 2)

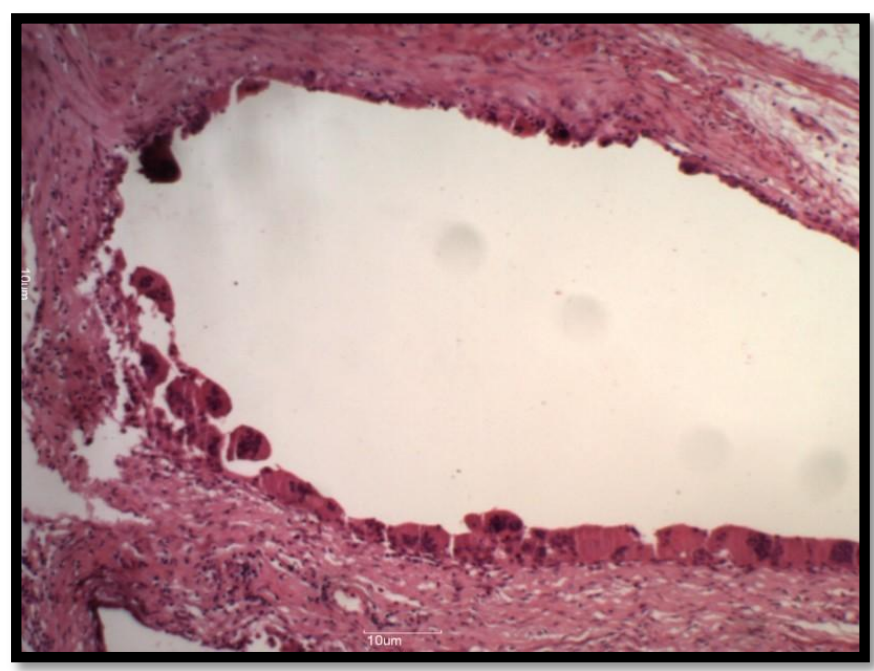

Fig.6 (40x) cystic space lined by histiocytic multinucleated giant cells. (Case 2)

\section{Discussion}

Various theories have been postulated in the development of PCI. One of these theories is the mechanical theory, according to which, the bowel gas gets pushed through a mucosal defect into lymphatic channels, and is then distributed distally by peristalsis ${ }^{(17)}$. This happens as a consequence to a bowel obstruction that may be caused by trauma, surgery and colonoscopy leading to increased intraluminal pressure ${ }^{[18]}$ thus explaining the association between these maneuvers and PCI. However this theory does not explain the high content of hydrogen present in the cysts ${ }^{[19]}$. The bacterial theory proposes that submucosal localization of fermenting Clostridia and Escherichia
Coli is the cause of production of gas which is retained by the submucosa and lymphatic channels. The pulmonary theory is demonstrated in patients with asthma and chronic bronchitis and argues that the gas freed by the rupture of the alveoli, travels through the mediastinum into the retroperitoneal space and then comes through the perivascular spaces in the intestinal wall ${ }^{[20]}$. PCI is seen to occur in two forms: benign and fulminant ${ }^{(21,22)}$. The fulminant form most often occurs in infants, as a complication of ischemic bowel injury. In such a scenario it probably results from mural invasion and overgrowth by gasforming bacteria with ensuing formation of gas cysts. The fulminant form rarely occurs in adults and is often associated with drugs or chemotherapy or with ischemic or pseudomembranous enterocolitis ${ }^{(23)}$ Adults more often demonstrate the benign form of PCI. Microscopically, fulminant PCI demonstrates gas cysts in the submucosa, augumenting the picture of ischemic bowel infarct with secondary bacterial overgrowth. The gas cysts are often ignored or mistaken for cutting artifact. In the benign form, an endothelial or histiocytic lining may be seen. Tears may occur in the submucosal connective tissue but, more typically, one encounters dilated cystic spaces that are lined totally or partially by endothelium, chronic inflammatory cells, histiocytes, and foreign body giant cells ${ }^{(23)}$. On biopsy material, Pneumatosis intestinalis remains a very challenging diagnosis, particularly because endoscopy rarely contributes. As entity PCI is usually confused with is crohns disease because of the presence of giant cells in the submucosa, variable inflammation and crypt disarray. Other differentials include intestinal polyps, cancer, inflammatory necrotizing enterocolitis, even if colonoscopy and biopsy are performed due to ignorance of PCI. To make a correct diagnosis attention to the arrangement of the giant cells lining the intact, partial or collapsed cysts is crucial. PCI has been associated with pulmonary disease in the absence of gastrointestinal disorders. In the $1^{\text {st }}$ case of our series, the patient 
had history of COPD. There is no unified standard for treatment of PCI. PCI is usually managed conservatively, however if peritoneal irritation or persistent bowel obstruction occurs, exploratory laparotomy is considered. It is also proposed that PCI could be effectively palliated with hyperbaric oxygen therapy at 2.5 atmospheres for $2.5 \mathrm{hrs}$ for at least three sessions ${ }^{(27,28)}$. Surgical treatment is indicated only if the patient is not responsive to conservative treatment or has developed serious adverse events.

\section{Conclusion}

PCI is an uncommon entity, diagnosis of which is often delayed due to lack of awareness and nonspecific clinical manifestations. Thus the clinicians and the endoscopists should be aware of the possible presentations of PCI in order to correctly manage the patients affected with this disease. PCI is often benign and only conservative treatment, and follow up is often warranted. The decision to proceed with explorative laparotomy must be based on the thorough analysis of a detailed history, physical examination, laboratory tests, and radiological studies.

\section{References}

1. Heng Y, Schuffler MD, Haggitt RC, Rohrmann CA. Pneumatosis intestinalis: a review. Am J Gastroenterol. 1995;90: 1747-58.

2. Read NW, Al-Janabi MN, Cann PA. Is raised breath hydrogen related to the pathogenesis of pneumatosis coli? Gut 1984; 25: 839-845

3. Koss LG. Abdominal gas cysts (pneumatosis cystoides intestinorum hominis); an analysis with a report of a case and a critical review of the literature.AMA Arch Pathol.1952; 53(6):523- 49.

4. McCollister DL, Hammerman HJ. Air, air, everywhere: pneumatosis cystoides coli after colonoscopy. Gastrointes Endosc 1990; 36: 75-76
5. Wandtke J, Skucas J, Spataro R, Bruneau RJ. Pneumatosis intestinalis as a complication of jejunoileal bypass. AJR Am J Roentgenol 1977; 129: 601-604.

6. Gagliardi G, Thompson IW, Hershman MJ, Forbes A, Hawley PR, Talbot IC. Pneumatosis coli: a proposed pathogenesis based on study of 25 cases and review of the literature. Int J Colorectal Dis 1996; 11: 111-118.

7. Sequeira W. Pneumatosis cystoides intestinalis in systemic sclerosis and other diseases. Semin Arthritis Rheum 1990; 19: 269- 277.

8. Duncan B, Barton LL, Eicher ML, Chmielarczyk VT, Erdman SH, Hulett RL. Medication-induced pneumatosis intestinalis. Pediatrics 1997; 99: 633-636.

9. Zimmerman AL, Gupta JK, Ingegno AP. Pneumatosis coli following treatment with lactulose. N Y State J Med 1979; 79:18961899.

10. Wu L-L, Yang Y-S, Dou Y, Liu Q-S. A systemic analysis of Pneumatosis cystoids intestinalis. World J Gastroenterol.2013;19 (August (30)):4973-8.

11. Wu L-L, Yang Y-S, Dou Y, Liu Q-S. A systemic analysis of pneumatosis cystoids intestinalis. World $\mathrm{J}$ Gastroenterol. 2013;19(August (30)):4973-8.

12. Khail PN, Huber-Wagner S, Ladurner R, Kleespies A, Siebeck M, Mutschler W,Halfeldt K, Kanz KG. Natural history, clinical pattern, and surgical consideration of pneumatosis interstialis. Eur $\mathbf{J}$ Med Res.2009;14(6):231-9.

13. Kanchela D, Vattikuti S, Vipperla K. Pnematosis cystoides intestinalis: is surgery always indicated? Cleve Clin J Med.2015;82(3):151-2.

14. Ogul H, Pirimoglu B, Kisaoglu A, Karaca L, Havan N, Ozogul B, Kantarci M. Pneumatosis cystoides intestinalis: an unusual cause of intestinal ischemia and 
pneumoperitoneum. Int Surg. 2015; 100(2): 221-4.

15. DuBose JJ, Lissauer M, Maung AA, Piper GL, O'Callaghan TA, Luo-Owen X,Inaba K, Okoye O, Shestopalov A, Fielder WD, Ferrada P, Wilson A, Channel J,Moore FO, Paul DB, Johnson S. Pneumatosis intestinalis predictive evaluation study (PIPES):a multicenter epidemiologic study of the eastern association for the surgery of trauma. J Trauma Acute Care Surg. 2013;75(1):15-23.

16. Xianyong Gui, Yi Zhou, Leslie Eidus, Vincent Falck, Zu-hua Gao, And Lihui Qin (2014) Is Pneumatosis Cystoides Intestinalis Gas-Distended and Ruptured Lymphatics?: Reappraisal by Immunohistochemistry. Archives of Pathology \& Laboratory Medicine: August 2014, Vol. 138,No. 8, pp. 1059-1066.

17. Galandiuk S, Fazio VW. Pneumatosis cystoides intestinalis. A review of the literature. Dis Colon Rectum 1986; 29: 358-363.

18. Heer M, Altorfer J, Pirovino M, Schmid M. Pneumatosis cystoides coli: a rare complication of colonoscopy. Endoscopy 1983; 15: 119- 120.

19. Gillon J, Tadesse K, Logan RF, Holt S, Sircus W. Breath hydrogen in pneumatosis cystoides intestinalis. Gut 1979; 20: 10081011.

20. St Peter SD, Abbas MA, Kelly KA. The spectrum of pneumatosis intestinalis. Arch Surg 2003; 138: 68-75.

21. Galandiuk S, Fazio VW. Pneumatosis cystoides intestinalis: a review of the literature. Dis Colon Rectum 1986;29: 358-363.

22. Heng Y, Schuffler MD, Haggitt RC, et al. Pneumatosis intestinalis: a review. Am J Gastroenterol 1995;90:1747-1758.
23. Koreishi A, Lauwers GY, Misdraji J. Pneumatosis intestinalis: a changing biopsy diagnosis. Am J Surg Pathol 2007;31:1469-1475.

24. Rottenstreich A, Agmon Y, Elazary R. A rare case of benign Pneumatosis intestinalis with portal venous gas and pneumoperitoneum induced by Acarbose. Intern Med.2015;54:1733-6.

25. Yanaru R, Hizawa K, Nakamura S, et al. Regression of pneumatosis cystoides intestinalis after discontinuing of alphaglucosidase inhibitor administration.J Clin Gastroenterol 2002;35:204-5.

26. Tsujimoto T, Shioyama E, Moriya K. Pneumatosis cystoides intestinalis following alpha-glucosidase inhibitor treatment: a case report and review of the literature. World J Gastroenterol. 2008;14(39):6087-92.

27. Feuerstein JD, White N, Berzin TM. Pneumatosis intestinalis with a focus on hyperbaric oxygen therapy. Mayo Clin Proc. 2014;89:697- 703.

28. Masterson JS, Fratkin LB, Osler TR, Trapp WG. Treatment of pneumatosis cystoides intestinalis with hyperbaric oxygen. Ann Surg. 1978;187:245-7. 